\title{
'Minding' the Style: Reading Conrad through Cognitive Poetics
}

\author{
Alireza Parandeh, Hossein Pirnajmuddin \\ Department of English Language and Literature, Faculty of Foreign Languages, \\ University of Isfahan, Azadi Square, Isfahan, Iran \\ E-mail address: parandeh_alireza@yahoo.com, pirnajmuddin@fgn.ui.ac.ir
}

\begin{abstract}
Keywords: Cognitive Poetics; Joseph Conrad; Mind Modeling; Theory of Mind; Impressionism; Deixis; Style
\end{abstract}

\begin{abstract}
Cognitive Poetics works on the triangle of author-text-reader. A main focus is the reader of literature, as a co-producer of the text alongside the author, in an attempt to explain how his/her knowledge and experiences are applied in reaching an understanding of a particular text in a particular context. In this paper several examples of how contextual frames can operate in a narrative are discussed in three works of short fiction by Joseph Conrad. Analyzed in the particular context of Conradian narrative and prose style are such points as: how the readers begin a story, how they enter into the interior levels of it in order to feel and touch the events in the way its characters do, how they follow every episode of it and, in other words, how the readers 'comprehend' the narrative. It is argued that the application of insights from cognitive poetics to Conrad's fiction is of particular relevance as Conrad is a writer who embodies and foregrounds this very act and process of 'comprehending' in his fiction.
\end{abstract}

\section{INTRODUCTION}

In this paper an attempt is made to shed some light on the modality of Conradian narrative and prose style by referring to insights from cognitive poetics, particularly those related to MindModeling. To this end, three works of short fiction by Conrad are selected: Typhoon, Youth and Amy Foster. It is argued that the application of these insights to the study of these works is especially relevant because they in a sense embody and foreground the very act and process of 'comprehension' of literature which is amply theorized in cognitive poetics.

Conrad is regarded as an influential figure in what has come to be termed literary modernism. In his impressionistic narratives and application of unreliable narrators, Conrad employed narrative techniques that became emblems of literary modernism (Stinson 45). An obvious feature of Conrad's writing style is his detailed and meticulous descriptions of his fictional settings and characters in a way that they are visualized in the mind of the reader. These visual qualities are referred to as Conrad's literary impressionism (Lothe 167).

Cognitive poetics as one of the recent approaches to the study of literature is defined by Stockwell as a "new way of thinking about literature, involving the application of cognitive linguistics and psychology to literary text" (Cognitive Poetics 1). It has close affinities with ReaderResponse criticism. As Tsur puts it, it explains the links between structure of a literary text and the received impressions. It makes effort to provide answers to basic questions of art, language and literature using insights from various disciplines such as linguistics, psychology, neuroscience and literary theory.

In what follows, first a number of theoretical notions in cognitive poetics are presented and then they are applied in analyzing the three above-mentioned works by Conrad. 


\section{DISCUSSION}

\subsection{Comprehension of Literature}

In Cognitive Poetics the readers play a central role in understanding a literary work. As Stockwell has proposed, "the engagement of the reader is not an 'add-on' feature but is an inherent part of the analytical theory from the beginning" (Cognitive Poetics, 136). Palmer believes that "our assumption that the story world will not depart from the real world unless we are told otherwise is a default position. So, when we study a narrative, we look for the clues that will tell us in what ways, if at all, the story world created by that narrative differs from the real world" (Social Mind, 55).

Readers of literature can comprehend a narrative by remembering and working out which character thinks, wants and feels what in the created context of the story, hence a written narrative would require the readers to construct an appropriate context around the words of the text (Emmott, 147). In reading a fiction the readers encounter new situations to which they must adapt their personality in order to understand it. However, as Stockwell mentions, "personality appears to be variable over time and yet feels consistent in the moment" ("Mind Modeling", 136). As Gibbs puts it, reading "is a skilled activity that relies on familiar knowledge and flexible, adaptive responses to novel situations" (27). This process relies mostly on the Theory of Mind which is a means of finding out the relations between fictional characters in a text, between characters and the readers of the text or between the narrator of the story and the reader (Belmonte, 192).

\subsection{Transportation through Literature}

Literature can gain its real meaning when it is read by some reader; one can go so far as to say that without the readers, literature does not exist at all; literature exists in the triangle of author, text and reader, not out of it. The readers study literature for different purposes the foremost of which is literary pleasure, gained while sinking deeply in its fictional world. Oatley classifies these intentions and effects as three main purposes; enjoyment, to become better writers and readers and to understand and improve our inner world (writingandreading 171). Readers mostly talk of their experience in reading literature by using the conceptual metaphor of transportation through literature, which is an inspired, cognitive and emotional projection, incorporated under the general notion of comprehension (Stockwell, Cognitive Poetics 151).

In reading/'comprehending' Conrad's fiction, it is virtually impossible for a reader not to imagine and identify the impressionistically portrayed settings and events. For example, in the scene depicting a raging storm in Typhoon, the reader experiences - feels - the tempestuous sea and the imminent danger of sinking. This simple instance is an instance of transportation through literature. For these kinds of transportations first there must be a traveler that is in fact the reader, one who adapts himself to new conditions, takes on assumed characteristics, attitudes, perceptions and beliefs, in order to make sense of the fictional scene. In order to engage in deictic projection, which helps us follow a character's point of view, the reader must take on an imagined model of that other point of perception and belief (Stockwell, Cognitive Poetics 152). In Conrad's case, these imaginary travels are of a different kind, owing to his detailed, experientially-oriented, vivid and impressionistic way of storytelling. After reading one of the stories such as Youth, the reader will close the book and return changed from his virtual travel, as if having finished a long and eventful sea travel to the East. If a reader does not feel so much moved by a work, he will very probably judge the book as a failure, since "the nature of the text (its architecture of formal patterns and genre characteristics) is the means of transport, and readers scale their evaluations of literary texts partly by how well they are seen to operate as vehicles of imaginary transportation" (ibid. 153).

All the transportations through literary worlds are caused by imagination, which is considered by Stockwell as a talismanic word at the core of cognitive studies (Cognitive Poetics 173). In Conradian narrative imagination is important both thematically and 'cognitively'; Conrad himself has proposed that "imagination, and not invention, is the supreme master of art as of life" (qtd. In Hunker 270). In Typhoon, for instance, imagination is put into question through an unimaginative character, Captain MacWhirr. Ian Watt describes MacWhirr as "the innocent, the natural, the wise fool, the man who is mocked by his fellows but who finally surprises them with a quite unexpected exhibition of real wisdom" (Essays on Conrad, 110). In Conrad's work generally, there are 
numerous examples of the at times ironic interrelationship between cognition and imagination and their failure; Watt, for instance, regards mist and haze as the most persistent images in Conrad's fiction (Conrad in the 19 $9^{\text {th }}$ century 169). In Typhoon, the captain's lack of imagination sometimes brings about the failure of cognition. MacWhirr is so unimaginative that he misses even simple points of irony. Talking about Siamese flag on the ship is a case in point:

Well, it looks queer to me," burst out Jukes, greatly exasperated, and flung off the bridge. Captain MacWhirr was amazed at these manners. After a while he stepped quietly into the chart-room, and opened his International Signal Code-book at the plate where the flags of all the nations are correctly figured in gaudy row. (Typhoon 10)

On the significance of the contrast between the characters of MacWhirr and Jukes, Pirnajmuddin proposes that "Ironically, it is Jukes, with his pretensions to racial superiority and intelligence, which is presented as the more uncomprehending, for MacWhirr, unlike Jukes, has no illusion of being understanding. Is not Conrad saying that those who have claims on understanding are in reality the more stupid?" (184).

Failure of cognition which ends in failure of communication is a frequent motif in Conrad. One more example is the episode of MacWhirr's wife reading her husband's letters carelessly and missing MacWhirr's unprecedented attempt to communicate. So is the ending of Amy Foster in which Amy, another unimaginative character, fails to understand that her dying husband asks for water.

In reading Conrad's fiction, the reader's attention and a part of his consciousness is on the sea, on the deck of the ship, in the storm or burning fire of the coal cargo, and he has become a part of that fictional world in a way that is not entirely metaphorical. For instance, in Typhoon, as Fraser has proposed, "in his graphic presentation of the storm and its twenty-minute period of calm, Conrad makes the time of the story and the time of the narrative as equal as possible. The result is to immerse readers in the 'real' ordeal and to emphasize the importance of 'direct' experience as a source of integrity and wisdom" (39). Stockwell mentions that a consequence of this immersion in the literary world is that some aspects of the real world such as our real knowledge would be inaccessible while reading literature (Cognitive Poetics 153). That is why in reading Typhoon or Youth, we know that they will survive the sea's rage, yet we feel anxious and excited about what is going on. Conrad's impressionistic technique brings about a more immediately felt and inevitable transportation, a fuller immersion of the reader in the narrative.

\subsection{Comprehension of Conradian Narrative}

\subsubsection{Contextual Frame Theory}

To find out how the readers follow the references to different characters and happenings during the process of reading, contextual frame theory was developed, which involves the basic notion of contextual frame, that is "a mental representation of circumstances containing the current context; this is built up from the text itself as well as from inferences drawn directly from the text" (Stockwell, Cognitive Poetics 155). About this theory Emmott argues that it

is a cognitive poetic theory because it shows that texts can be studied not only for their style, but also to provide clues to the amount of work that a reader has to do to process the language. In this respect, a detailed analysis of a text can reveal the extent to which a reader's knowledge, beliefs, assumptions and inference-making ability are necessary to supplement (and in some cases override) the words on the page. Contextual frame theory is similar to Text World Theory, but it focuses particularly on how contexts within fictional worlds are constructed. (146)

Apart from Text World Theory, there are close ties between contextual frame theory and other cognitive theories such as the theory of mental spaces and the theory of possible worlds. The 
reader's background knowledge and experiences from the real world is of great significance in contextual frame theory, by which he can fill the gaps in the course of the reading. As Palmer states, "with all other aspects of the reading process, we bring our real-world cognitive frames to bear when we encounter fictional intermental units" (Social Minds 49). In order to advance the plot, more and more frames are constructed by textual clues such as deixis. The first matter to discuss in this regard is the notion of primed frame. Stockwell argues that "as the narrative moves on, different contexts move into the primary focus: the current frame that is being monitored is said to be primed. When the reader's attention is taken elsewhere, that frame and all its contents become unprimed" (Cognitive Poetics 156). Emmott also defines primed frame as "the mental representation of the context in which the reader feels that he/she is actively witnessing the action as it unfolds" (146). In creating and understanding primed frames, deixis plays the major role in a text, since it is like a leading sign for the reader to follow the narrative. In what follows several examples of this framing are discussed in Conrad's fiction.

The main narrative in Youth begins by its narrator with these sentences: "We were sitting round a mahogany table that reflected the bottle, the claret-glasses, and our faces as we leaned on our elbows" (89). Here is created the first deictic center and of course the first frame of the story which is to be primed several times during the reading process. Sometimes in the course of a narrative, when a frame is primed, there are some mental representations of various contexts that are embedded within that primed context or frame, but they are not expanded in sufficient detail for the reader to consider them as primed. Emmott calls these frames "projected frames" (148). In Amy Foster, for instance, when the narrator and his friend Kennedy are hanging out in the village, they see Amy in front of her cottage and a frame is primed in this way:

A woman, in full sunlight, was throwing a dripping blanket over a line stretched between two old apple-trees. And as the bobtailed, long-necked chestnut, trying to get his head, jerked the left hand, covered by a thick dog skin glove, the doctor raised his voice over the hedge: "How's your child, Amy? (Amy Foster 205)

In this scene, although the primed frame is on Amy's cottage, there also is created a projected frame when Kennedy asks a question about Amy's child, not presented in this frame but inferred by the reader, who is probably at home and who was sick earlier. In Youth, perhaps the most palpable projected frame is that of the coal hold in the ship when it starts burning:

The smell down below was as unexpected as it was frightful. One would have thought hundreds of paraffin-lamps had been flaring and smoking in that hole for days. I was glad to get out. The man with me coughed and said, 'Funny smell, sir. (Youth 102)

The frame of coal burning is a projected frame since the reader is not provided with any information about it except for the idea that it is a kind of hole-like hold, burning and extracting smoke and smell, so there is not enough information for the scene of burning to be primed until the time the sailors decide to go into the hold and find the origin of smoke under the coal cargo; this is when the frame becomes primed for a short time. A primed frame can also be modified in the course of the narrative. These frame modifications can happen when for example a character enters or leaves a frame. This is called modification of the frame since all other things about the context remain stable; however, the frame at the end is different from the frame at the beginning, but it would be the same modified frame (Stockwell, Cognitive Poetics 156). Different examples of frame modification would be found in Typhoon, especially during the storm. At the end of chapter three, captain MacWhirr and Jukes are talking and the primed frame is created on the deck with these two characters, but suddenly an officer enters the frame: 
He pulled himself up by Jukes' coat, taking that liberty with the greatest moderation, and only so far as it was forced upon him by the hurricane. "What is it, boss'n, what is it?" yelled Jukes, impatiently. What could that fraud of a boss'n want on the bridge? The typhoon had got on Jukes' nerves. The husky bellowings of the other, though unintelligible, seemed to suggest a state of lively satisfaction. There could be no mistake. The old fool was pleased with something. The boatswain's other hand had found some other body, for in a changed tone he began to inquire: "Is it you, sir? Is it you, sir?" The wind strangled his howls. "Yes!" cried Captain MacWhirr. (Typhoon 49)

In this scene frame is modified by the entering of the boatswain, when everything remains the same as before his appearance, but again the modified frame is different from the first primed frame since after his appearance, the pre-existing characters are informed of a fact when in the rest the boatswain tells the captain:

All that the boatswain, out of a superabundance of yells, could make clear to Captain MacWhirr was the bizarre intelligence that "All them Chinamen in the fore 'tween deck have fetched away, sir. (Typhoon 49)

There is also constructed a projected frame in this part which is about the Chinese men aboard the ship. Although just enough information is offered here to make the scene of this event primed for the reader, he will be aware of what has happened on the other side of the ship through a projected mental representation of the event. Similarly, in the final scene of Amy Foster, a conspicuous and perhaps the most crucial frame modification occurs when Amy leaves her husband to die with a great fear:

He sat up and called out terribly one word - some word. Then he got up as though he hadn't been ill at all, she says. And as in fevered dismay, indignation, and wonder he tried to get to her round the table, she simply opened the door and ran out with the child in her arms. She heard him call twice after her down the road in a terrible voice - and fled... Ah! (Amy Foster 238)

After Amy's misunderstanding of Yanko's speech and failure of cognition and communication, she runs out of the cottage with the child and Yanko remains alone. The frame remains the same here except for Amy's absence when it is modified. After modification in spite of the same setting, Yanko's mindset is changed and he approaches his death.

A frame can be primed for a time, and then be replaced with another frame in the course of a narrative. Stockwell notes that "most literary narratives include frame switch as a feature apparent in their structural organization. The frame is switched in a reader's mind by a change in location, most typically realized linguistically by a spatial locative. Large jumps in time, realized by temporal locatives, also create frame switches" (Cognitive Poetics 157). An example of frame switches can be seen at the very beginning of Youth, when the first frame is created and primed by the unknown narrator, then it is switched to another frame by the time Marlow begins narrating his own story directly:

Marlow (at least I think that is how he spelt his name) told the story, or rather the chronicle, of a voyage: "Yes, I have seen a little of the Eastern seas; but what I remember best is my first voyage there. (Youth 89)

Stockwell calls this type of frame switch instantaneous (Cognitive Poetics 157), since it happens very rapidly by some spatial deictic terms; also there are other sorts of switches which occur slowly as the narrative goes on. An example of this switching is the scene in which Marlow and other sailors leave their ship. Here the frame switch occurs slowly and in the course of the narrative not 
faster than it. In the above excerpt, when Marlow begins his story, the frame is switched to another one, but the previous primed frame remains potentially there to be switched back to. In this case, when the unprimed frame is available to be primed again, a frame recall can occur (ibid. 157). Frame recalls are very common in Youth, through the flashbacks and flashforwards to the bar and the ship. Sometimes these frame recalls which bring about the first frame to be primed again happen only through the very simple phrase "pass the bottle," that brings the narrative back to the bar with old Marlow and his friends around the table.

In order to comprehend a narrative, the readers must keep track not only of the narrative, but also of the various belief systems of its characters. However, it is possible that a reader rejects some or all of a belief frame that is created by a character. An example of this kind of frame is when MacWhirr reads the manual of navigation to find out what to do in the forthcoming storm:

He tried to bring all these things into a definite relation to himself, and ended by becoming contemptuously angry with such a lot of words, and with so much advice, all head-work and supposition, without a glimmer of certitude. "It's the damnedest thing, Jukes," he said. "If a fellow was to believe all that's in there, he would be running most of his time all over the sea trying to get behind the weather. (Typhoon 33)

In this excerpt MacWhirr states his opinion about the insufficiency of the technical book on navigation and indeed all. Though the reader may disagree with the captain's view, he has to keep track of it to make sense of the following parts of the story and to feel MacWhirr's lack of imagination more intimately. Of course at the end of the narrative the reader may change his idea about him and share his view of such 'bookish' knowledge. In one of the scenes in Amy Foster, when Kennedy and his friend offer their ideas oabout the character of Amy, a belief frame is created with which the reader may agree or disagree:

She seems a dull creature," I remarked listlessly. "Precisely," said Kennedy. "She is very passive." (Amy Foster 205).

In following different belief frames of characters, their changes and their states of minds, as they develop in a narrative, there figures the notion of enactor. There can be several enactors of one character in a story. Stockwell defines an enactor as "versions of the character at different points in the narrative" (Cognitive Poetics 157). For example, when a character recalls his youth and younger self, another enactor of that character is created. Stockwell adds that enactors are bound to different frames in a story and cannot exist in the same frame unless in supernatural or science fictional narratives (ibid. 157). In reading fiction, the reader's job is to keep track of many different enactors and compress them into a notion of a single character, remember which frame they are attached to and keep a sense of what each enactor believes, knows and thinks.

Readers of literature have the capacity to imagine different worlds, each of which is filled with various enactors. The text world of the older Marlow in Youth, recalling his earlier life, includes a flashback and frame switch to another world level or frame, in which there is a younger enactor of Marlow. Of course, though Marlow is the apparent narrator of his story, we know that these words in the text are actually composed by the implied author, Joseph Conrad, a being above all enactors of Marlow, and one who has shared a discourse world with the reader. The notion of enactor is very helpful in finding out what happens in the reader's mind during the reading process and in discovering how he follows the events and keeps track of a character throughout a narrative course by attaching his own mind to that of the character.

\subsubsection{Delayed Decoding}

Stockwell has proposed that "sometimes readers make mistakes and sometimes texts provide cues that deliberately mislead the reader in order to provide suspense, shock or a satisfying plot resolution. In all these cases, a frame repair is made. An element of a frame is reinterpreted and the 
frame is modified retrospectively" (Cognitive Poetics 157). The notion of frame repair is closely related to the Conradian technique of "delayed decoding" whereby making sense of an event for both the characters and the reader is delayed. Peters mentions two purposes for this strategy:

First, it places the reader in the position of the character viewing the event so that the reader experiences what the character does at the very moment that character experiences it, thus providing a realism and immediacy to the reader's experience. Second, delayed decoding emphasizes the tenuous nature of human perception, demonstrating that what one experiences filters through one's consciousness and hence is subjective and not objective. (48)

Watt believes that this technique "takes us directly into the observer's consciousness at the very moment of the perception, before it has been translated into its cause" (Conrad in the Nineteenth Century p. 175). An example of delayed decoding is found in Youth, in the scene of the explosion in the ship hold:

I said curtly, 'Don't, Chips, ' and immediately became aware of a queer sensation, of an absurd delusion,--I seemed somehow to be in the air. I heard all round me like a pentup breath released--as if a thousand giants simultaneously had said Phoo!--and felt a dull concussion which made my ribs ache suddenly. No doubt about it--I was in the air, and my body was describing a short parabola. But short as it was, I had the time to think several thoughts in, as far as I can remember, the following order: 'This can't be the carpenter--What is it?--Some accident--Submarine volcano?--Coals, gas!--By Jove! we are being blown up--Everybody's dead--I am falling into the after-hatch-I see fire in it. (Youth 105)

First Marlow does not figure out what has happened to him; while he is in the air several thoughts occur to his mind such as a volcanic eruption or a mistake by the carpenter. With these reported thoughts, Marlow misguides the reader for a short while, and then it is revealed to both Marlow and the reader that the coal has exploded beneath. As we go through Marlow's thoughts, several projected frames are created within the primed frame of the deck, which lead the reader to some other hypotheses about the event; but when Marlow utters these words "Coals, gas!--By Jove! we are being blown up," the primed frame is reinterpreted and repaired for the reader and other potential frames fade away.

\subsubsection{Mind-modeling}

So far we have tried to show the special relevance to Conrad's fiction of insights provided by Cognitive Poetics, particularly the notion that a reader's mind can be modeled, adapted, revised and changed. Highlighted is how a reading occupies a part of the reader's consciousness through the process of mind-modeling; a process which can change the reader at least temporarily during the time of the reading. This change is related to the very fact of being able to step into a literary world and realize its fictional people. The feelings, beliefs and experiences that a reader brings to the reading process are brought to bear in his mind-modeling of a character; this modeling means that characters start off with an equivalent of the reader's consciousness, his sense of perception and emotions, and in a single word, his embodiment.

Stockwell maintains that mind-modeling brings about strength in the feelings of a reader for a character ("Mind Modeling" 141). There are also some experimental works that show readers construct mental models after characters in a narrative by adopting their perspective; for instance, participants in a study as the readers, verified that they can remember the objects more readily if they are associated with a character in one way or another, even when they share the place of an object with a character (Gibbs, 37). This fact shows how a reader's consciousness is engaged with that of a character during the reading process in a way that he even sees better from the character's 
perspective, not from his own one. Accordingly, we can say that every character is the reader until the text in hand directs him into describing how they are dissimilar; that is why a reader's model of a character is richer than what the textual depictions can account for. Palmer holds that almost all the physical events described in a narrative are perceived by its characters and have an impact on their mental functioning, "otherwise why mention them?" He believes that events have significance only if they are experienced by characters, for which he has proposed the notion of "fictional minds" ("Universal Minds" 208). In reading fiction, readers attach themselves to these fictional minds in order to experience everything as it is experienced by a character, through modeling his mind after a fictional character's mind. Palmer explains that:

The key to fictionality is the construction of fictional minds. A fictional narrative is, in essence, the presentation of the mental functioning of the characters who inhabit the storyworld created by that narrative. Readers enter a storyworld primarily by using their knowledge of how to interpret other people's thought processes in the real world in order to try to follow the workings of characters' minds. Otherwise, readers will lose the plot. (ibid. 205)

Mind-modeling begins by the reader's ability to assume a Theory of Mind in other people, and act and speak accordingly. Belmonte defines Theory of Mind (TOM) as a "specific capacity underlying certain sorts of beliefs about what people are thinking" (196). He adds that the modes of application are different; psychological TOM is "an online, real time process applied during the act of interpreting behavior", whereas literary TOM is "an offline, temporally extended process applied during the act of reading" (ibid. 192). Stockwell explains that the capacity for TOM refers to the general ability to figure out that other people have a belief system about the world which is different from our own, and the result of running one's TOM is that one attributes certain beliefs about the world to others; in this process, a person constructs a theory that others have minds that operate in the same way as his own ("Mind Modeling" 137). Readers of fiction have to use their TOM in order to keep track of workings of characters' minds, otherwise they will lose the plot of the narrative; moreover, the readers have to follow the TOM of every character of other characters, including the filtering TOM of the narrator which is of greater importance than others. Palmers has proposed that "a minimal level of mind reading and Theory of Mind is required for characters to understand each other and thereby make everyday life possible" (Social Mind 47).

Building of fictional minds can be done on the basis of simply several sentences, which the reader then psychologizes and fleshes out into a rich character through his Theory of Mind; this means a fictional person possesses the same basic human characteristics as the reader does, unless the text sets out specific differences. We may sometimes apply our TOM to some object in the real world, when for example we shout at our computer if it does not work properly. In Conrad's fiction, the readers find many examples of running a TOM to objects, especially to the ship. "For Conrad a ship is something with human attributes. Like woman, it must be lived with to be understood" (Hunker 275). An example of this case is when Marlow and other sailors are going to leave Judea in Youth, and all look at it as a real person sinking in water:

Between the darkness of earth and heaven she was burning fiercely upon a disc of purple sea shot by the blood-red play of gleams; upon a disc of water glittering and sinister. A high, clear flame, an immense and lonely flame, ascended from the ocean, and from its summit the black smoke poured continuously at the sky. She burned furiously, mournful and imposing like a funeral pile kindled in the night, surrounded by the sea, watched over by the stars. A magnificent death had come like a grace, like a gift, like a reward to that old ship at the end of her laborious days. (Youth 115)

There are some other instances where Marlow and in fact Conrad, as the implied author, applies his TOM to the ship like when he describes ships movements on the sea waves: 
There was no rest for her and no rest for us. She tossed, she pitched, she stood on her head, she sat on her tail, she rolled, she groaned, (Youth 95)

A good example of applying readers' TOM to fictional characters is the scene of pumping water out and in; the sailors are trying hard to save their ship and the reader can feel and touch their tiredness, sleepiness, thirst, hunger and even their diminishing hope by applying his TOM to them and modeling his mind after them:

We pumped watch and watch, for dear life; and it seemed to last for months, for years, for all eternity, as though we had been dead and gone to a hell for sailors. We forgot the day of the week, the name of the month, what year it was, and whether we had ever been ashore. (Youth 96)

Without the ability to apply one's TOM to characters, one cannot even imagine the scene and the imminent danger, let alone the inner feelings of each character. As Stockwell mentions, "a text world account also allows mind-modeling to be extended to non-belief domains such as the imagined desires, wishes and physical needs (hunger, lust, thirst, sleepiness, and so on) of others" ("Mind Modeling" 138). In other words, one who suffers a lack of TOM cannot appreciate the minds and perspectives of others. There is an example of this sort of person in Typhoon in the character of captain MacWhirr. Captain MacWhirr is mostly self-focused and has little awareness of other characters' mental states. MacWhirr seems to have a Theory of Mind problem; he does not feel like to talk about shared mental states with others, since he does not have a fully developed ability to understand the working of other characters' minds and their perspectives. In writing letters to his wife, he sometimes shows signs of a TOM but certainly not a developed one.

In the case of Amy Foster, the importance of language in application of TOM to others so as to understand them is demonstrated, specifically in Yanko's relationships with the villagers and even with Amy. At the end of the story Amy escapes from the cottage in a fright and leaves the terminally ill Yanko alone; this happens owing to a failure of communication which is the result of a failure in cognition that is in turn the consequence of Amy's inability in applying her TOM to Yanko. In his semi-conscious state, Yanko begins talking in his native language which frightns Amy away; however, it was Amy who ran her TOM to Yanko, understood his hunger and fetched him a piece of bread when he was jailed. This paradox indicates that the more and the greater the common ground among the characters within a narrative and among the characters and the readers of the narrative, the more possible it is for them to apply their TOMs and consequently the more enhanced the mind-modeling of the characters and finally a better comprehension of the story.

Stockwell explains that every reading process involves a personal relationship among real people out in the world and fictional people in the world of a fiction ("Mind Modeling" 136); hence, identification of the reader with fictional characters is an integral part of every reading process, especially that of a fiction. He adds that "personality is never entirely stable in itself [....] Personality is adaptive to the conditions at hand. In literary encounters, if personality were rigid and fixed, immovable and inextensible, then it would be impossible to engage with or appreciate viewpoints that were distant from our own" (ibid. 135). This flexibility of personality causes the pleasure that originates from literature when a reader can place himself in a character's place and gives that character a sense of impersonation. Peters considers Conrad as one of the authors who make great efforts to replace the reader with the character in the course of the narrative (83).

Readers sometimes feel a sense of identification and sympathy with fictional characters even more than with real people, which is caused by the process of simulation, through which the reader feels the same things as the character does. Stockwell defines simulation as a type of mental projection that a reader sets up when he is engaged with a literary world; he explains that the same feelings are involved in the reading process, as in real life situations (Cognitive Poetics 172). Simulation is in fact imagining oneself as the other person (fictional character) in order to feel his perceptions, emotions and beliefs; this process explains a lot about the power of literature. In the 
light of these theories one can surmise what happens to a reader when he encounters the scene of a fierce storm on the deck of Nun-Shan, or when sailors are pumping water into Judea to extinguish the fire and save their lives.

One reason that readers feel moved and transported by a literary work is that they have committed a part of their own identity and consciousness to the world created in that work; accordingly, there is a degree of emotional engagement in modeling fictional minds, since emotions are seen as being communicative in cognitive psychology (Stockwell, Cognitive Poetics 172). Palmer maintains that cognition and emotions are inseparably tied in a way that cognition causes emotions and emotions bring about cognition; he adds that we cannot even imagine a novel with all the emotions and feelings taken out, since it would not make any sense because "emotions drive narratives" ("Universal Mind" 213). The result of this processing of cognition and emotions in the same way is the effects of literature on its reader and on the real world where they live (Stockwell, Cognitive Poetics 152). We can conclude that the emotional engagement of the readers of Conrad's fiction, particularly the adventure stories associated with the sea, with the characters of the stories and the events is of paramount importance. Indeed, it is what Conrad is keen on throwing into high relief. For example, in the final scene of Amy Foster, it is not possible to comprehend the climax of the story if the reader is not emotionally engaged with the narrative when he is reading the last words uttered by Yanko. Without emotions a reader will remain on the surface of the narrative. In Youth, when Marlow reaches the end of his story, not only the reader but also the listeners around the table seem to be emotionally moved; the unknown narrator concludes the whole narrative by saying:

our faces marked by toil, by deceptions, by success, by love; our weary eyes looking still, looking always, looking anxiously for something out of life, that while it is expected is already gone--has passed unseen, in a sigh, in a flash--together with the youth, with the strength, with the romance of illusions. (Youth 122)

Stockwell believes that emotions generated by a literary work is the same as emotions generated in real life circumstances, the only difference is in their degree, not in their kinds, because in both situations the cognitive mechanisms are the same (Mind Modeling" 137). After all, we can infer that the final comprehension of a literary work is not just the representation of the propositional content of its text, but more significantly, it includes the personal and social effects that a text can cause, alongside the felt experience in the reading process on the reader.

\section{CONCLUSION}

Half of the creation of a text is in the hands of its writer and the other half is in the hands of its reader who brings the text into existence; this is the core concept of Cognitive Poetics. In this study, we took a look at three works of short fiction by Conrad through the lenses of Cognitive Poetics. We tried to shed light on why Conrad is called "a painter doubled by a psychologist" (Huneker 270). By his special impressionistic mode of storytelling and the masterly use of the technique of delayed decoding, Conrad paves the way for the reader to travel to the world of his fiction through different contextual frames, their switches, modifications and re-callings. The most important means of this journey is the reader's power of imagination. Conrad's fiction seems to be an uncanny putting into practice of notions theorized in cognitive poetics, notions such as mindmodeling which tries to explain how a reader's mind changes through the process of reading, how it detaches itself from the real world and sees the story through the characters' perspectives. As protomodernist or early modernist works, the Conradian narratives incorporate a significant element of metafictionality in that they somehow enact and embody the very process of cognition involved in (reading) fiction. This is of course achieved through Conrad's uniquely self-conscious - and 'mind'-conscious - style. 


\section{References}

[1] Belmonte, Matthew K. "Does the experimental scientist have a theory of mind?" Review of General Psychology 12.2 (2008): 192-204.

[2] Conrad, Joseph. Typhoon and Other Tales. Oxford: Oxford University Press, 1986.

[3] --- Typhoon and Youth. London: William Heinemann LTD, 1954.

[4] Emmott, Catherine. "Reading For Pleasure: A Cognitive Poetic Analysis of 'twists in the tale' and Other Plot Reversals in Narrative Texts." Cognitive Poetics in Practice. eds. Gavins, Joanna, and Gerard Steen. London, Routledge, 2003. 145-159.

[5] Fraser, Gail. "The Short Fiction." Cambridge Companion to Joseph Conrad. ed. Stape, J.H. Cambridge: Cambridge University Press, 1996. 25-44.

[6] Gavins, Joanna, and Gerard Steen, eds. Cognitive Poetics in Practice. London: Routledge, 2003.

[7] Gibbs, Raymond W. "Prototypes in dynamic meaning construal." Cognitive Poetics in Practice. eds. Gavins, Joanna, and Gerard Steen. London, Routledge, 2003. 27-40.

[8]Huneker, James. "The Genius of Joseph Conrad." The North American Review 200.705 (1914): 270-279.

[9] Lothe, Jakob. “Conradian narrative.” Cambridge Companion to Joseph Conrad. ed. Stape, J.H. Cambridge: Cambridge University Press, 1996. 160-178.

[10] Oatley, Keith. "Writingandreading: The Future of Cognitive Poetics." Cognitive Poetics in Practice. eds. Gavins, Joanna, and Gerard Steen. London, Routledge, 2003. 161-173.

[11] Palmer, Alan. "Universal minds." Semiotica 2007.165 (2007): 205-225.

[12] ---Social minds in the novel. Ohio State University Press, 2010.

[13] Pirnajmuddin, Hossein. "Of Books and Letters: The Ending of Joseph Conrad's Typhoon." The Explicator 67.3 (2009): 183-186.

[14] Stinson, Emmett. "Literary and Cultural Contexts: Major Figures, Institutions, Topics, Events." eds. Tew, Philip, and Alex Murray, The modernism handbook. Bloomsbury Publishing, 2009. 43-65.

[15] Stockwell, Peter. Cognitive Poetics: An Introduction. London: Routledge, 2002.

[16] --- "Mind-Modeling." Texture: A cognitive aesthetics of reading. ed. Hoffmann, Thomas. Edinburgh University Press, 2012. 134-144.

[17] Tsur, Reuven. Toward a theory of cognitive poetics. Amsterdam: North-Holland, 1992.

[18] Watt, Ian P. Conrad in the nineteenth century. Vol. 1. University of California Press, 1979.

[19] --- Essays on Conrad. Cambridge: Cambridge University Press, 2003. 